\title{
Correction to: Benefit-Cost Analysis of the Danish Sun Safety Campaign 2007-2015: Cost Savings from Sunburn and Sunbed Use Reduction and Derived Skin Cancer Reductions 2007-2040 in the Danish Population
}

\author{
Brian Køster $^{1}$ (D) . Maria K. H. Meyer ${ }^{1} \cdot$ Jes Søgaard $^{2} \cdot$ Peter Dalum $^{1}$
}

Published online: 5 November 2019

(c) The Author(s) 2019

\section{Correction to: PharmacoEconomics Open https://doi.org/10.1007/s41669-019-00182-x}

Abstract, Results, first sentence, which previously read:

"The results were based on a reduction of 9000 skin cancer cases, saving $€ 47$ million of which $€ 29$ million were derived from sunburn reductions and $€ 16$ million from reductions in sunbed use."

should have read:

"The results were based on a reduction of 9000 skin cancer cases, saving $€ 29$ million of which $€ 13$ million were derived from sunburn reductions and $€ 16$ million from reductions in sunbed use."

Section 1 Introduction, third paragraph, third sentence, which previously read:

The original article can be found online at https://doi.org/10.1007/ s41669-019-00182-x.

Brian Køster

Koester_brian@yahoo.com

Maria K. H. Meyer

Marmey@ cancer.dk

Jes Søgaard

jsoegaard@health.sdu.dk

Peter Dalum

pd@cancer.dk

1 Department of Prevention and Information, Danish Cancer Society, Strandboulevarden 49, 2100 Copenhagen $\varnothing$, Denmark

2 Danish Centre for Health Economics, Department of Public Health, University of Southern Denmark, Odense, Denmark
"The skin cancer projections (2007-2040) also showed reductions in the number of skin cancer cases of more than 30,000 and 14,000 as a result of reductions in sunbed use and sunburn, respectively, compared with no change in behavior $[12,13] . "$

should have read:

"The skin cancer projections (2007-2040) also showed reductions in the number of skin cancer cases of 16,000 and 14,000 as a result of reductions in sunbed use and sunburn, respectively, compared with no change in behavior $[12,13]$."

Section 3 Results, first paragraph, third sentence, which previously read:

"In total, the campaign is estimated to have avoided more than 9000 cases of skin cancer in the conservative scenario."

should have read:

"In total, the campaign is estimated to have avoided nearly 9000 cases of skin cancer in the conservative scenario."

Section 3 Results, first paragraph, fifth sentence, which previously read:

"Skin cancer reductions due to reductions in sunburn have cost savings of almost $€ 13$ million, sunbed use $€ 34$ million, and combined $€ 47$ million."

should have read: 
"Skin cancer reductions due to reductions in sunburn have cost savings of almost $€ 13$ million, sunbed use $€ 16$ million, and combined $€ 29$ million."

The article has now been updated to correct the errors.

Open Access This article is distributed under the terms of the Creative Commons Attribution-NonCommercial 4.0 International License (http://creativecommons.org/licenses/by-nc/4.0/), which permits any noncommercial use, distribution, and reproduction in any medium, provided you give appropriate credit to the original author(s) and the source, provide a link to the Creative Commons license, and indicate if changes were made. 